\title{
A New Method of Obtaining Transparent Conducting Films of Indium (III) Oxide and Indium-Tin Oxide
}

\author{
Natalia P. Fadeeva*a, \\ Svetlana V. Saikova ${ }^{a, b}$, Elena V. Pikurovaa, \\ Anton S. Voroninc, Yuri V. Fadeev ${ }^{c}$, \\ Alexander S. Samoilob and Igor A. Tambasov ${ }^{d}$ \\ ${ }^{a}$ Institute of Chemistry and Chemical Technology SB RAS \\ Krasnoyarsk, Russian Federation \\ ${ }^{b}$ Siberian Federal University \\ Krasnoyarsk, Russian Federation \\ ${ }^{c}$ Federal Research Center «Krasnoyarsk Science Center SB RAS» \\ Krasnoyarsk, Russian Federation \\ ${ }^{d}$ Kirensky Institute of Physics SB RAS \\ Krasnoyarsk, Russian Federation
}

\begin{abstract}
In the work, sedimentation-stable sols of indium (III) and tin (IV) hydroxides were obtained by the Anion Resin Exchange Precipitation, which consists of the exchange reaction between the $\mathrm{OH}$ ions of the anion exchange resin and the anions of metal-containing solutions. The synthesized hydrosols were used to obtain conducting films of indium (III) $\mathrm{In}_{2} \mathrm{O}_{3}$ oxide and indium oxide doped with Tin $\mathrm{In}_{2} \mathrm{O}_{3}$ : Sn, with a surface resistance of $4 \mathrm{kOhm} / \mathrm{sq}$, thicknesses of 200-500 $\mathrm{nm}$ and a transparency of more than $85 \%$. The modes of applying precursors to glass substrates by the modified spray method and centrifugation method are selected. Films were studied using XRD, SEM, optical microscopy and spectrophotometry.
\end{abstract}

Keywords: films, indium oxide, indium tin oxide, anion resin exchange synthesis.

Citation: Fadeeva N.P., Saikova S. V., Pikurova E. V., Voronin A. S., Fadeev Yu.V., Samoilo A. S., Tambasov I. A. A new method of obtaining transparent conducting films of indium (III) oxide and indium-tin oxide, J. Sib. Fed. Univ. Chem., 2021, 14(1), 45-58. DOI: 10.17516/1998-2836-0215

(c) Siberian Federal University. All rights reserved

This work is licensed under a Creative Commons Attribution-NonCommercial 4.0 International License (CC BY-NC 4.0).

* Corresponding author E-mail address: yevsevskaya@mail.ru 


\title{
Новый метод получения прозрачных \\ проводящих пленок оксида индия (III) \\ и оксида индия-олова
}

\author{
Н.П. Фадеева ${ }^{\mathrm{a}}$, С. В. Сайкова ${ }^{\mathrm{a}, \boldsymbol{\sigma}}$, \\ Е. В. Пикурова ${ }^{a}$, А. С. Воронин ${ }^{\text {, }}$ \\ Ю. В. Фадеев ${ }^{\text {, }, ~ А . ~ С . ~ С а м о и ̆ л о б, ~ И . А . ~ Т а м б а с о в ~}{ }^{\text {г }}$ \\ ${ }^{a}$ Институт химии и химической технологии ФИЦ КНЦ СО РАН \\ Российская Федерация, Красноярск \\ ${ }^{6}$ Сибирский федеральный университет \\ Российская Федерация, Красноярск \\ ${ }^{8}$ ФИЦ «Красноярский научный изентр СО РАН» \\ Российская Федерачия, Красноярск \\ ${ }^{2}$ Институт физики им. Л. В. Киренского ФИЦ КНЦ СО РАН \\ Российская Федерация, Красноярск
}

\begin{abstract}
Аннотация. В работе получены седиментационно устойчивые золи гидроксидов индия (III) и олова (IV) методом анионообменного синтеза, заключающимся в обменной реакции между ОН-ионами анионообменной смолы и анионами металлосодержащих растворов. Синтезированные гидрозоли использованы для получения проводящих пленок оксида индия (III) $\operatorname{In}_{2} \mathrm{O}_{3}$ и оксида индия, легированного оловом $\operatorname{In}_{2} \mathrm{O}_{3}: \mathrm{Sn}$, с поверхностным сопротивлением 4 кОм/кв, толщинами 200 500 нм и прозрачностью более 85 \%. Подобраны режимы нанесения прекурсоров на стеклянные подложки модифицированным спрей-методом и методом центрифугирования. Пленки исследованы с помощью РФА, СЭМ, оптической микроскопии и спектрофотометрии.
\end{abstract}

Ключевые слова: пленки, оксид индия, оксид индия-олова, анионообменный синтез.

Цитирование: Фадеева, Н.П. Новый метод получения прозрачных проводящих пленок оксида индия (III) и оксида индия-олова / Н. П. Фадеева, С. В. Сайкова, Е. В. Пикурова, А.С. Воронин, Ю. В. Фадеев, А. С. Самойло, И. А. Тамбасов // Журн. Сиб. федер. ун-та. Химия, 2021, 14(1). С. 45-58. DOI: 10.17516/1998-2836-0215

\section{Введение}

Оксиды индия (III) $\operatorname{In}_{2} \mathrm{O}_{3}$ и индия-олова $\operatorname{In}_{2} \mathrm{O}_{3}$ : $\mathrm{Sn}$ (ITO - indium tin oxide) полупроводники n-типа с относительно низким удельным электрическим сопротивлением 10-10 рокой фундаментальной запрещенной зоной $(>2,89 \mathrm{eV})$. Для них также характерно высокое пропускание в видимой области спектра $~ 90 \%$ и сильное отражение в инфракрасной области [1-4]. Данные материалы широко применяются для производства жидкокристаллических и плазменных дисплеев, солнечных элементов, оптико-электронных устройств, оснащенных сенсорными экранами, и высокочувствительных газовых сенсоров $[5,6]$.

Различные подходы к получению тонких (толщиной до нескольких микрон) пленок ITO и оксида индия (III), представленные в литературе, можно разделить на два вида: физические 
и химические. В широко распространенных физических методах вещество мишени переносится на подложку под влиянием различных энергетических воздействий [7-11]. Эти методы позволяют получать высококачественные покрытия с низким поверхностным сопротивлением, достигающим 10-15 Ом/кв, однако требуют создания вакуума и дорогостоящего оборудования.

Химические методы, например золь-гель метод $[12,13]$ или метод химического осаждения из газовой фазы (CVD процесс) $[14,15]$, не требуют сложного аппаратурного оформления и позволяют получать покрытия с поверхностным сопротивлением вплоть до 100 Ом/кв [6]. Однако их использование сопряжено с необходимостью тщательного контроля условий синтеза во избежание микронеоднородностей в системе. Например, при проведении зольгель синтеза необходимо тщательное регулирование скорости гидролиза прекурсоров. Кроме того, требуется применение дорогих гелеобразующих компонентов, а сам синтез весьма длителен.

Процесс CVD-осаждения относительно сложен и требует контроля многих факторов: температура и давление в рабочей камере, скорость откачки, концентрация паров исходного соединения, наличие добавок к парам исходного соединения и т. д. Также для CVD-осаждения существуют высокие требования к прекурсорам, они должны быть достаточно летучими, чтобы испаряться при относительно низкой температуре и, реагируя с подложкой, давать сплошную тонкую пленку. Таким образом, разработка недорогих и простых методов получения тонких пленок на основе оксида индия является актуальной проблемой.

Предлагаемый в данной работе метод получения пленок $\operatorname{In}_{2} \mathrm{O}_{3}$ и ITO заключается в формировании равномерных пленок гидроксидов металлов (прекурсоров) на стеклянных подложках с последующей термообработкой покрытий. Синтез прекурсоров проводится запатентованным авторами методом анионообменного осаждения [16, 17], основанным на реакциях между ионами ионообменной смолы (например, $\mathrm{OH}^{-}$) и водным раствором, содержащим соль металла:

$$
\begin{aligned}
& \mathrm{InA}_{3}+3 \mathrm{ROH}=\operatorname{In}(\mathrm{OH})_{3}+3 \mathrm{RA}, \\
& \mathrm{SnA}_{4}+4 \mathrm{ROH}=\mathrm{Sn}(\mathrm{OH})_{4}+4 \mathrm{RA},
\end{aligned}
$$

где R-матрица анионита, $\mathrm{A}=\mathrm{Cl}^{-}, \mathrm{NO}_{3}^{-}, 1 / 2 \mathrm{SO}_{4}^{2-}$.

В ходе реакций 1 и 2 происходит связывание ионов металлов гидроксид-анионами, образующимися в ходе ионного обмена, в малорастворимые продукты. Путем подбора условий синтеза можно получать устойчивые гидроксидные золи $[18,19]$. Смола в этом случае не только служит источником ОН-ионов, но и сорбирует мешающие примесные анионы исходных растворов, что обеспечивает необходимую чистоту продукта без дополнительных стадий очистки. Процесс протекает в стационарном режиме при постоянном значении $\mathrm{pH}$, что способствует образованию однородных по составу, структуре, размеру и морфологии частиц прекурсоров [20]. Стоит отметить, что аниониты, применяемые для синтеза, являются недорогими коммерчески доступными реагентами, традиционно применяемыми в водоподготовке и водоочистке для бытовых и промышленных нужд, а также немаловажно, что после проведения синтеза аниониты подлежат регенерации и могут использоваться многократно. 
Цель данной работы - подбор условий синтеза стабильных золей гидроксидов индия (III) и олова (IV) методом анионообменного осаждения, получение на их основе проводящих пленок $\operatorname{In}_{2} \mathrm{O}_{3}$ и ITO с содержанием олова 10 \%, а также исследование их структурных, электрических и оптических свойств.

\section{Материалы и методы}

В работе использовали следующие реактивы: $\mathrm{SnCl}_{4} \cdot 5 \mathrm{H}_{2} \mathrm{O}, \mathrm{In}_{2}\left(\mathrm{SO}_{4}\right)_{3} \cdot 5 \mathrm{H}_{2} \mathrm{O}, \mathrm{In}\left(\mathrm{NO}_{3}\right)_{3} \cdot 4.5 \mathrm{H}_{2} \mathrm{O}$, $\mathrm{InCl}_{3} 3 \mathrm{H}_{2} \mathrm{O}$ (все Sigma-Aldrich, $99.99 \%$ ), гелевый сильноосновный анионит AB-17-8 (ГОСТ 20301-74, фирма ПАО «АЗОТ»), цетилтриметиламмоний бромид (ЦТАБ, Biochem), $\alpha-1.4-; \alpha-1.6-$ глюкан (пуллулан, Hayashibara). Подготовку анионита к эксплуатации и определение его обменной емкости проводили по методикам, описанным в [21]. Статическая обменная емкость анионита в гидроксидной форме составляла 1.6 ммоль-экв/г.

\section{Синтез прекурсоров}

Анионообменный синтез золя $\operatorname{In}(\mathrm{OH})_{3}$ проводили следующим образом: навеску сухого AB-17-8(OH), рассчитанную по формуле 3 , заливали дистиллированной водой для набухания и приводили в контакт с $0.25 \mathrm{M}$ раствором нитрата индия при постоянном перемешивании на магнитной мешалке 200 мин $^{-1}$ при комнатной температуре в течение 25 мин. Аналогично синтез вели для получения прекурсора ITO: 0.25 М раствор, содержащий $\mathrm{In}\left(\mathrm{NO}_{3}\right)_{3}$ и $\mathrm{SnCl}_{4}$ ( $\mathrm{In}: \mathrm{Sn}=9: 1$ по массе), приводили в контакт с рассчитанным по формуле 4 количеством анионита. Соотношение In:Sn=9:1 по массе оптимально для ITO, поскольку при таком содержании олова достигается максимальная концентрация и подвижность свободных носителей заряда $[22,23]$. Для отделения анионита использовали сито с диаметром отверстий 0.1 мм.

$$
\begin{aligned}
& m_{\text {апиопита }}=\frac{\left(C_{I n} \cdot V_{I n}\right) \cdot 1,5 \cdot 3}{C O E}, \\
& m_{\text {анионита }}=\frac{\left(C_{I n} \cdot V_{I n}\right) \cdot 1,5 \cdot 3+\left(C_{S n} \cdot V_{S n}\right) \cdot 1,5 \cdot 4}{C O E},
\end{aligned}
$$

где $\mathrm{C}_{\mathrm{In}}, \mathrm{C}_{\mathrm{Sn}}$ - концентрации исходных растворов индия (III) и олова (IV); $\mathrm{V}_{\mathrm{In}}, \mathrm{V}_{\mathrm{Sn}}$ - объемы исходных растворов; СОЕ - статическая обменная емкость, ммоль-экв $\Gamma^{-1}$.

Удельную электропроводность реакционных растворов измеряли на приборе Мультитест КСЛ-101 (НПП «Семико», Россия, г. Новосибирск).

\section{Нанесение пленок}

Для формирования равномерных пленок прекурсора на стеклянных подложках применяли два подхода: модифицированный спрей-метод и метод центрифугирования (spin coating). В первом случае использовали ультразвуковое диспергирование гидрозолей прекурсора (ультразвуковой ингалятор «РОТОР» Муссон-1М, рабочая частота 2.64 МГц), что позволило обойти проблему макроскопических неоднородностей, возникающую при использовании обычного распыления [24]. Получившийся аэрозоль подается в рабочую камеру, где разбивается потоком воздуха о подложку (рис. 1a). Время единичного напуска аэрозоля составляло 5 с, сушка слоя в потоке воздуха -5 мин. Количество слоев определялось предварительными экспериментами и составляло 25. 
Формирование пленок центрифугированием осуществлялось на центрифуге для нанесения тонких пленок и фоторезиста СТН-3.80.7.НИК (ООО «НПК Спецтехнаука», Россия, г. Красноярск). 100 мкл гидрозоля, содержащего прекурсор, наносили на стеклянную подложку по всей поверхности и центрифугировали на скоростях 2500 об/мин в течение 1 мин, высушивали при температуре $80{ }^{\circ} \mathrm{C}$ с помощью ИК-нагревателя, интегрированного в установку, охлаждали до комнатной температуры и повторяли нанесение прекурсора (рис. 1б). Оптимальное количество слоев, исходя из предварительных экспериментов, составляло 10.

a

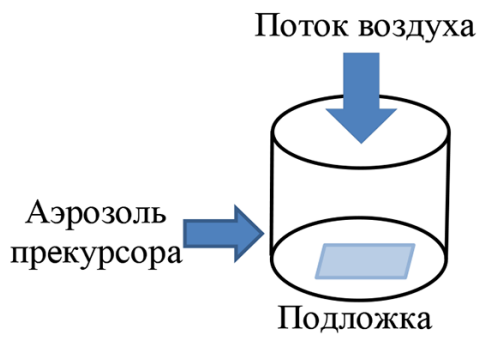

6

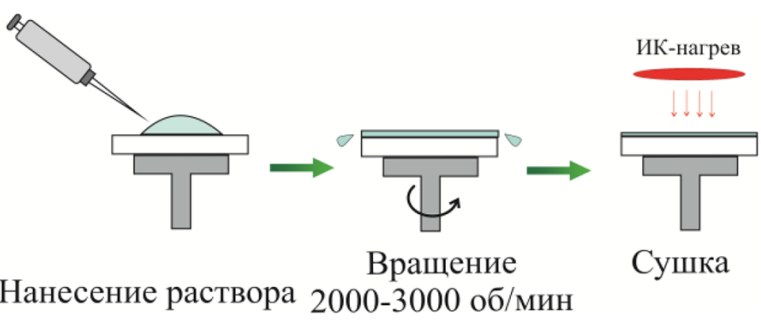

Рис. 1. Схема формирования пленок прекурсоров ITO и $\operatorname{In}_{2} \mathrm{O}_{3}$ модифицированным спрей-методом (а) и методом центрифугирования (б)

Fig. 1. Formation scheme of the precursors films of ITO and $\mathrm{In}_{2} \mathrm{O}_{3}$ by the modified spray method (a) and by the centrifugation method (б)

Стеклянные подложки размером $2.5 \times 2.5$ см подготавливали следующим образом: промывка водой с ПАВ (додецилсульфат натрия, 5 \%), обработка $1 \mathrm{M} \mathrm{NaOH}$, промывка дистиллированной водой, ультразвуковая обработка в дистиллированной воде при $70{ }^{\circ} \mathrm{C}$, сушка на воздухе.

Полученные пленки прекурсоров отжигались в CVD-печи «Домна» (OOO «НT-МДТ СИ», Россия, Зеленоград) в течение 1 ч при $450{ }^{\circ} \mathrm{C}$ в потоке $\mathrm{N}_{2}(10$ л/ч).

Съемка рентгенограмм осуществлялась на пленках в диапазоне углов $5^{\circ}<2 \Theta<70^{\circ}$ с шагом $0.03^{\circ}$ и скоростью сканирования 1.5 град/мин на автоматизированном рентгеновском дифрактометрическом оборудовании фирмы Shimadzu XRD-7000S (излучение $\mathrm{CuK}_{\alpha}$ ). Рентгенофазовый анализ проводили с использованием информационно-поисковой системы рентгенофазовой идентификации материалов, совмещающей качественный и полуколичественный анализ (по методу «корундовых чисел»).

Макроструктуру пленок изучали при помощи оптического микроскопа Альтами-104 (OOO «Альтами», Россия, г. Санкт-Петербург). Для исследования микроструктуры пленок использовали сканирующий электронный микроскоп Hitachi S5500 (Hitachi Ltd., Япония).

Спектральная зависимость коэффициента пропускания $\mathrm{T}(\lambda)$ получена на спектрофотометре Shimadzu-UV 3600 (Shimadzu Corp., Япония) в диапазоне длин волн 400-1500 нм. Определение оптического пропускания тонких пленок выполняли с учетом френелевского отражения от границ стеклянной подложки.

Вольтамперные характеристики (BAX) тонких пленок определяли с помощью измерителя параметров полупроводниковых приборов (ИППП-1, ОАО «МНИПИ», Беларусь, г. Минск). 
ВАХ были исследованы на образцах квадратной формы размером $25 \times 25 \times 1$ мм при постоянном токе и при комнатной температуре по методике, описанной в [24].

\section{Обсуждение результатов}

На анионообменное осаждение золей $\operatorname{In}(\mathrm{OH})_{3}$ существенно влияет концентрация и тип аниона исходной соли. Ранее было показано, что при использовании низких концентраций катионов металлов $(<0.15 \mathrm{M})$ наблюдается невысокая скорость процесса, и установлено ее оптимальное значение -0.25 моль/л [25].

С целью исследования влияния типа аниона исходной соли индия на скорость и полноту его осаждения определяли изменение удельной электропроводности реакционных растворов от времени. Поскольку в ходе процесса происходит сорбция анионов исходных солей ионитом и связывание образующихся при обмене ОН-ионов и ионов металла в гидроксид, наблюдается снижение удельной электропроводности (рис. 2). В случае $\mathrm{In}_{2}\left(\mathrm{SO}_{4}\right)_{3}$ электропроводность реакционных растворов резко уменьшалась в первые три минуты процесса и в течение 30 мин достигала равновесного значения 9 мСм/м. Однако при этом формировался плотный белый осадок. При использовании $\mathrm{InCl}_{3}$ и $\mathrm{In}\left(\mathrm{NO}_{3}\right)_{3}$ процесс шел медленнее: равновесное значение электропроводности (50 и 100 мСм/м соответственно) достигалось в течение 60 мин, но приводило к образованию гидрозолей. Золь, полученный из $\operatorname{In}\left(\mathrm{NO}_{3}\right)_{3}$, обладал большей седиментационной устойчивостью: образования осадка не наблюдалось в течение суток, в то время как из золя, полученного из $\mathrm{InCl}_{3}$, через 2 ч после окончания синтеза выпадал осадок. В целом полнота осаждения индия уменьшалась в ряду $\operatorname{In}_{2}\left(\mathrm{SO}_{4}\right)_{3}>\mathrm{InCl}_{3}>\operatorname{In}\left(\mathrm{NO}_{3}\right)_{3}$, что согласуется с рядом селективности анионита AB-17-8 по отношению к данным анионам [26, 27].

В дальнейшем анионообменный синтез прекурсоров проводили из нитратных растворов, обеспечивающих получение агрегативно и седиментационно устойчивых золей. В случае со-

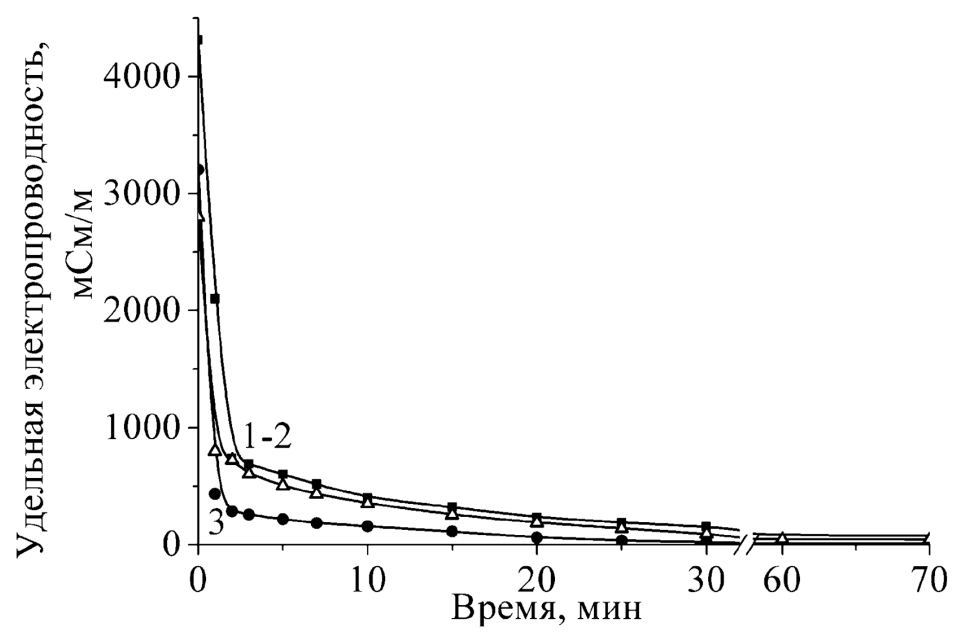

Рис. 2. Изменение удельной электропроводности реакционных растворов: $1-\operatorname{In}\left(\mathrm{NO}_{3}\right)_{3} ; 2-\mathrm{InCl}_{3} ; 3-$ $\mathrm{In}_{2}\left(\mathrm{SO}_{4}\right)_{3}$ со временем

Fig. 2. Change of the specific electrical conductivity of the reaction solutions: $1-\operatorname{In}\left(\mathrm{NO}_{3}\right)_{3}, 2-\operatorname{InCl}_{3}, 3-\mathrm{In}_{2}\left(\mathrm{SO}_{4}\right)_{3}$ with time 
вместного осаждения индия и олова также образовывался стабильный золь. Все полученные продукты не содержали примесных анионов (предел обнаружения $1 \cdot 10^{-6}$ моль/л).

Свежеприготовленный золь наносили на стеклянные подложки модифицированным спрей-методом и с помощью центрифугирования (табл. 1, образцы 1 и 2), в результате чего, независимо от используемого метода нанесения, получены непроводящие пленки с выраженной островковой структурой (средний размер островков 50-100 мкм, промежутков - от 5 до 60 мкм, рис. $3 a, \sigma)$. Вероятно, испарение воды в процессе сушки слоев привело к агломерации частиц с образованием глобул.

Таблица 1. Влияние условий синтеза прекурсоров и параметров их нанесения на величину поверхностного сопротивления и оптическое пропускание покрытий

Table 1. Influence of the precursor synthesis conditions and parameters of their application on the surface resistance and optical transmission of coatings

\begin{tabular}{|c|c|c|c|c|c|}
\hline $\begin{array}{c}\text { № } \\
\text { образца }\end{array}$ & $\begin{array}{c}\text { Исходная } \\
\text { соль }\end{array}$ & Добавки & $\begin{array}{c}\text { Способ } \\
\text { нанесения }\end{array}$ & $\begin{array}{c}\text { Поверхностное } \\
\text { сопротивление, } \\
\text { кОм/кв }\end{array}$ & Пропускание, \% \\
\hline 1 & \multirow{6}{*}{$\operatorname{In}\left(\mathrm{NO}_{3}\right)_{3}$} & \multirow{2}{*}{$\begin{array}{c}\text { Без } \\
\text { добавок }\end{array}$} & Спрей & $>10^{8}$ & - \\
\hline 2 & & & Центрифугирование & $>10^{8}$ & - \\
\hline 3 & & \multirow{2}{*}{ ЦТАБ } & Спрей & 196 & 89.92 \\
\hline 4 & & & Центрифугирование & $>10^{8}$ & - \\
\hline 5 & & \multirow{2}{*}{ Пуллулан } & Спрей & $>10^{4}$ & - \\
\hline 6 & & & Центрифугирование & 203 & 70.65 \\
\hline 7 & \multirow{2}{*}{$\mathrm{In}\left(\mathrm{NO}_{3}\right)_{3}+\mathrm{SnCl}_{4}$} & ЦТАБ & \multirow{2}{*}{ Центрифугирование } & $>10^{8}$ & - \\
\hline 8 & & Пуллулан & & 4 & 85.96 \\
\hline
\end{tabular}

Для стабилизации формирующихся гидрозолей и предотвращения процессов агломерации использовали стабилизаторы: ЦТАБ (концентрация $8 \cdot 10^{-4} \mathrm{M}$, ниже критической концентрации мицеллообразования [28]) или пуллулан (0.065 мас. \%). В случае пуллулана, который является полисахаридным полимером с пленкообразующими свойствами, подбиралась такая его концентрация, при которой вязкость раствора не препятствовала образованию аэрозоля для осуществления спрей-процесса.

Добавка стабилизаторов, улучшив седиментационную устойчивость получаемых золей (образования осадка не наблюдалось в течение нескольких месяцев), отрицательно сказалась на их реологических свойствах, что привело к необходимости поиска оптимального варианта нанесения золей на подложку в случае каждого использованного стабилизатора. При центрифугировании толщина и однородность пленок зависят от многих факторов: от вязкости и состава золя, поверхностного натяжения, состояния поверхности подложки, а также от параметров процесса - скорости вращения центрифуги, температуры, влажности окружающей среды $[29,30]$. Так, в случае ЦТАБ метод центрифугирования не смог обеспечить равномерного распределения частиц гидрозолей по поверхности подложки, а также их достаточной адгезии. По данным оптической микроскопии (табл. 1, образцы 4 и 7, рис. 32 

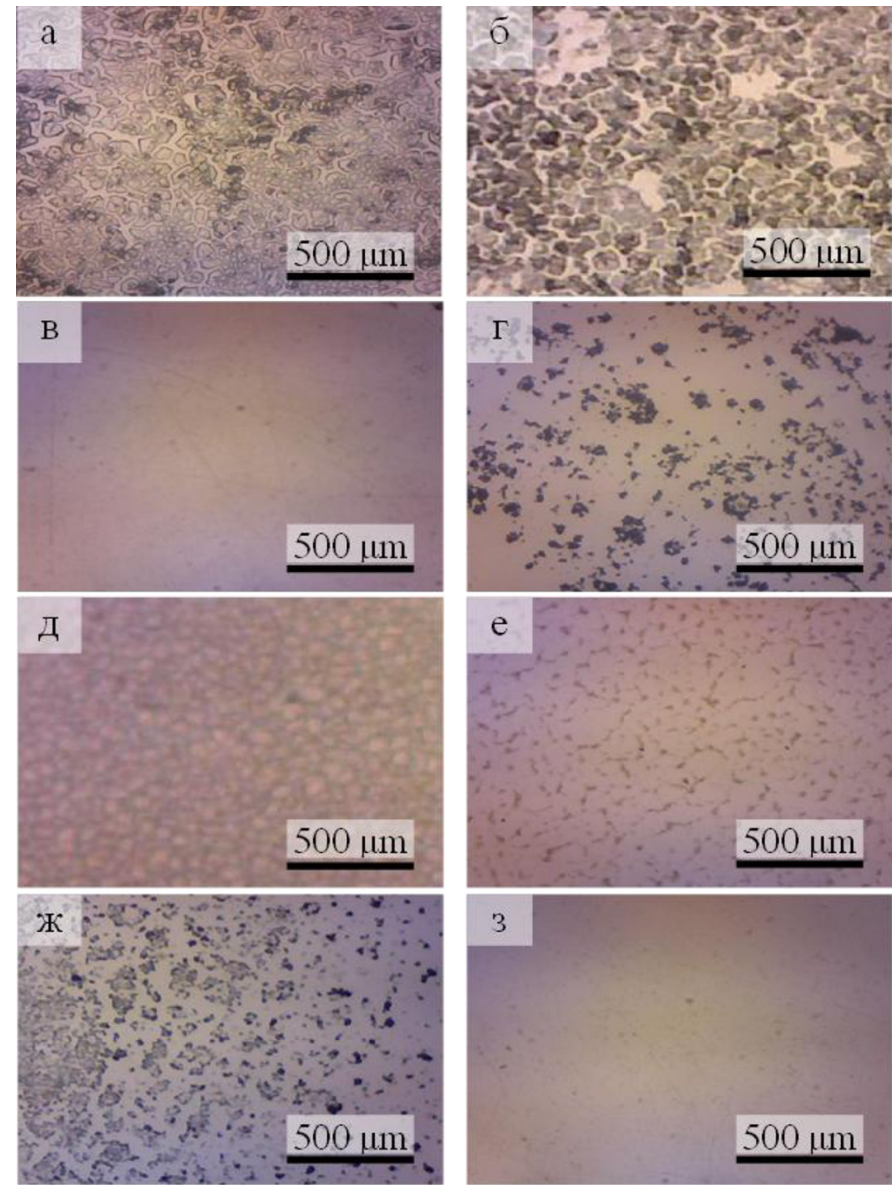

Рис. 3. Микрофотографии (оптическая микроскопия) полученных пленок (а)-(3): образцы 1-8 соответственно (табл. 1)

Fig. 3. Micrographs (optical microscopy) of the obtained films (a) - (3): samples 1-8, respectively (Table 1)

и 3ж), площадь покрытых участков составляет только $30-40$ \%. В результате получены непроводящие пленки.

Однако пленка $\operatorname{In}_{2} \mathrm{O}_{3}$ (табл. 1, образец 3), изготовленая спрей-методом с использованием ЦТАБ, равномерно покрывает подложку (рис. 3в) и имеет однородную структуру и поверхностное сопротивление 196 кОм/кв. Напротив, покрытие, полученное спрей-методом в присутствии пуллулана (табл. 1, образец 5), имеет зернистую структуру (рис. 3d) и демонстрирует более высокое поверхностное сопротивление (>10 МОм/кв). Очевидно, что добавка ЦТАБ приводит к растеканию капель аэрозоля по подложке в отличие от пуллулана. Вероятно, что в процессе сушки потоком воздуха происходит интенсивное испарение жидкой фазы из золя и вязкость золя с добавкой пуллулана существенно увеличивается, что препятствует равномерному растеканию капель аэрозоля. При использовании метода центрифугирования в присутствии пуллулана (табл. 1, образец 6) на подложке образуется сплошная пленка, обладающая поверхностным сопротивлением 203 кОм/кв и низким оптическим пропусканием (около 70 \%) вследствие заметного рельефа (рис. $3 e$ ). 
Добавка оксида олова одновременно повысила прозрачность и проводимость формирующейся пленки (табл. 1, образец 8). По данным микроскопии (рис. 33), покрытие имеет однородную структуру, а его рельеф сглажен.

Рентгенофазовый анализ пленок $\mathrm{In}_{2} \mathrm{O}_{3}$ и ITO, обладающих наименьшим поверхностным сопротивлением (табл. 1, образцы 3 и 8), показал (рис. 4), что в обоих случаях получены монофазные продукты без признаков присутствия других фаз. В первом случае спектр соответствует кубической фазе $\operatorname{In}_{2} \mathrm{O}_{3}$ [JCPDS01-083-3348]. В спектре ITO наблюдается небольшой сдвиг дифракционных максимумов по сравнению со стандартным значением межплоскостных расстояний, что характерно для оксида индия, кубической модификации, легированного оловом [31]. Положение максимумов соответствует оксиду индия-олова состава $\left(\operatorname{In}_{1.88} \mathrm{Sn}_{0.12}\right) \mathrm{O}_{3}$ [JCPDS01-089-4598].

Для оценки среднего размера кристаллитов применяли формулу Дебая-Шерерра. Расчет для образца 3 был проведен по трем наиболее интенсивным дифракционным максимумам (222), (400) и (440), для образца 8 использован пик (222). Средний размер нанокристаллитов для пленок оксида индия и ITO составил 36 и 19 нм соответственно. Возможно, уширение дифракционных максимумов ITO является следствием небольшого искажения решетки оксида индия из-за возникновения взаимодействия между атомами олова [32].

По данным СЭМ (рис. 5), пленка $\mathrm{In}_{2} \mathrm{O}_{3}$ (табл. 1, образец 3), полученная спрей-методом в присутствии ЦТАБ (25 слоев), имеет толщину 400-500 нм, а покрытие ITО (табл. 1, образец 8), синтезированное за 10 нанесений, более тонкое - 210-250 нм.

На рис. 6 приведены спектры оптического пропускания стеклянной подложки без (1) и с нанесенными покрытиями $\operatorname{In}_{2} \mathrm{O}_{3}$ и ITO (табл. 1, образцы 3 и 8). В видимом диапазоне длин волн полученные образцы достаточно хорошо пропускают свет, коэффициент пропускания более 80 \%. Так, на длине волны 550 нм пропускание пленки $\operatorname{In}_{2} \mathrm{O}_{3}$ составляет 89.92 \%, а ITO -

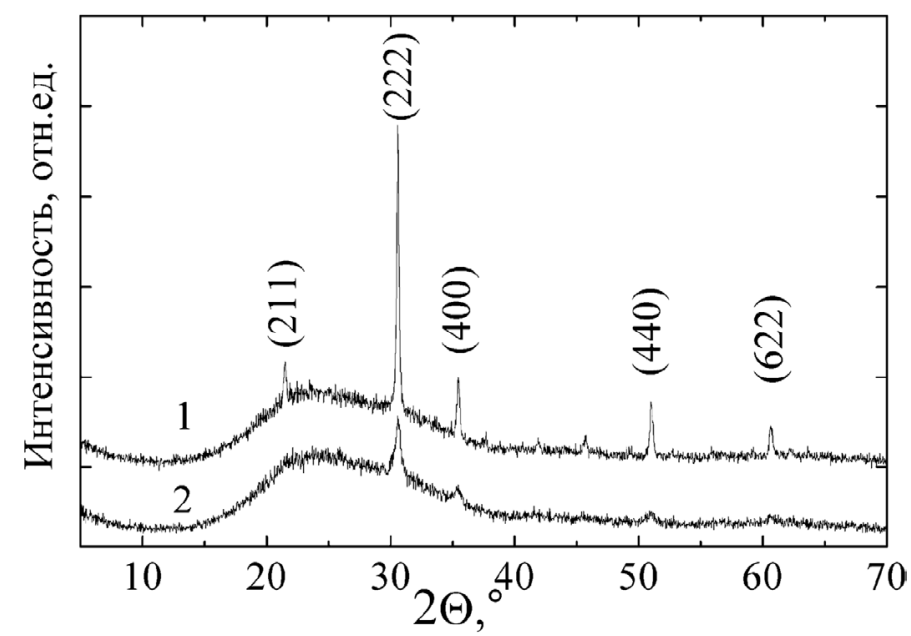

Рис. 4. Рентгенограммы синтезированных пленок $\operatorname{In}_{2} \mathrm{O}_{3}-$ кривая 1 и ITO - кривая 2 (табл. 1, образец 3 и 8 соответственно)

Fig. 4. X-ray diffraction patterns of the synthesized $\operatorname{In}_{2} \mathrm{O}_{3}$ films - curve 1 and ITO - curve 2 (Table 1 , sample 3 and 8 , respectively) 

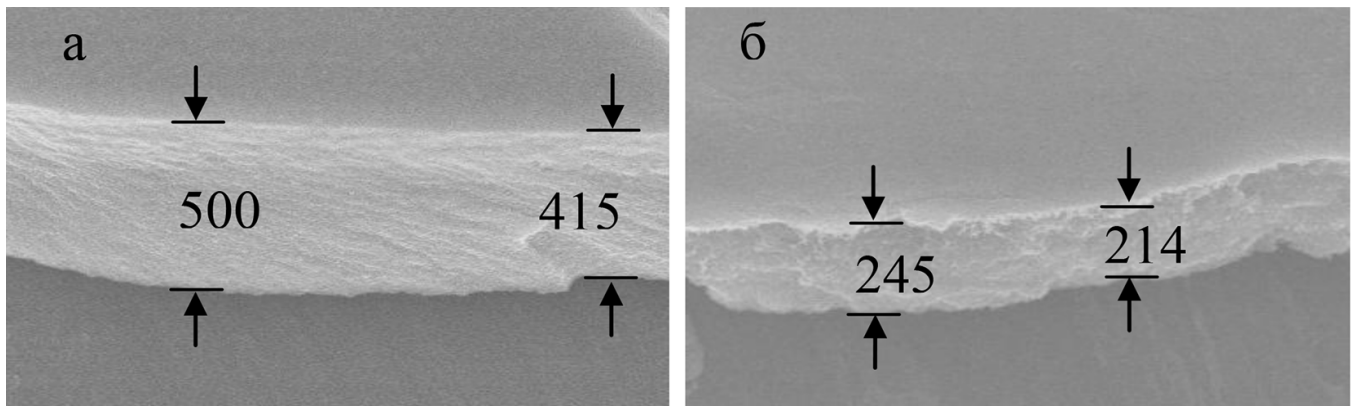

Рис. 5. Микрофотографии (СЭМ) поперечного среза пленок $\operatorname{In}_{2} \mathrm{O}_{3}$ (а) и ITO (б) (табл. 1, образец 3 и 8 соответственно)

Fig. 5. Micrographs (SEM) of a cross section of (a) $\operatorname{In}_{2} \mathrm{O}_{3}$ and (б) ITO films (Table 1, samples 3 and 8, respectively)

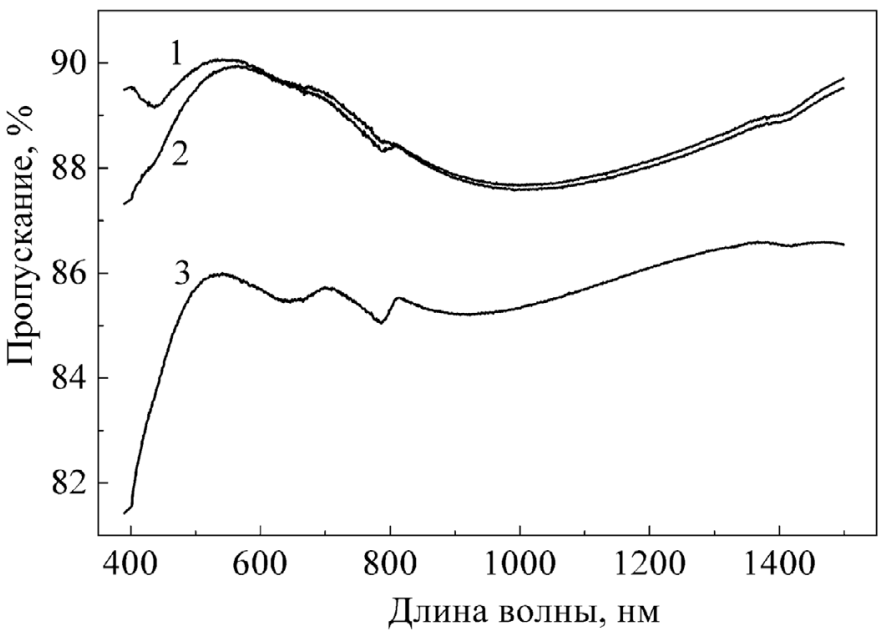

Рис. 6. Спектры пропускания тонких пленок на стеклянных подложках: 1 - чистая стеклянная подложка; 2 - подложка - $\mathrm{In}_{2} \mathrm{O}_{3} ; 3$ - подложка - ITO (табл. 1, образцы 3 и 8 соответственно)

Fig. 6. Transmission spectra of thin films on glass substrates: 1 - clean glass substrate; $2-\operatorname{substrate}-\mathrm{In}_{2} \mathrm{O}_{3}$; 3 - substrate - ITO (Table 1, samples 3 and 8 , respectively)

85.96 \%. Судя по литературным данным, уменьшение пропускания ITO связано с более высоким количеством носителей заряда по сравнению с $\operatorname{In}_{2} \mathrm{O}_{3}$ [33].

На рис. 7 представлены вольт-амперные характеристики, измеренные для тонких пленок оксида индия (рис. 7a) и ITO (рис. 7б). ВАХ полученных пленок имеют линейный характер, что свойственно для омического контакта и говорит об однородности полученных пленок. Удельное электрическое сопротивление, по данным вольт-амперных характеристик с учетом толщин тонких пленок, составляет 9 и 0.1 Ом·см для оксида индия и ITO соотвественно.

Пленки $\mathrm{In}_{2} \mathrm{O}_{3}$ со схожими электрическими характеристиками (удельная проводимость 0.16-6.9 (Ом·см $\left.)^{-1}\right)$ были получены в [34] с помощью метода плазменно-термического испарения, для осуществления которого необходимо сложное вауумное оборудование. А в работах $[35,36]$ получены пленки ITO с близкой к нашим проводимостью 0.1-50 кОм/кв. Однако авторы применяли органические реагенты, которые подвергались высокотемпературному разложе- 

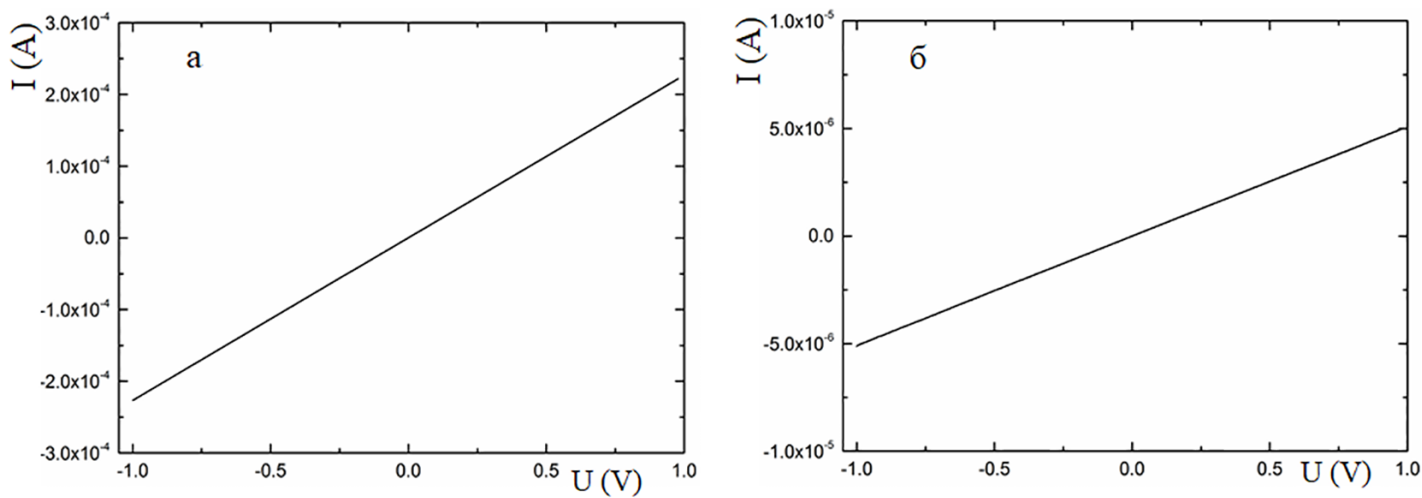

Рис. 7. Вольт-амперные характеристики синтезированных пленок ITO (а) и $\operatorname{In}_{2} \mathrm{O}_{3}$ (б) (табл. 1, образцы 8 и 3 соответственно)

Fig. 7. Current-voltage characteristics of the synthesized films ITO (а) и $\operatorname{In}_{2} \mathrm{O}_{3}$ (б) (Table 1, samples 8 and 3 , respectively)

нию с образованием оксидов углерода, в том числе $\mathrm{CO}, \mathrm{CH}_{3} \mathrm{COOH}$, ацетона и следов углеводородов [37]. Предлагаемый в данной работе метод не предполагает использования легколетучих органических реагентов, а значит, является более экологичным.

\section{Заключение}

Подобраны условия и отработаны методики получения гидрозолей гидроксида индия методом анионообменного осаждения с использованием сильноосновного анионита AB-17-8(OH). Установлено, что агрегативно и седиментационно устойчивые золи образуются из $0.25 \mathrm{M}$ раствора $\operatorname{In}\left(\mathrm{NO}_{3}\right)_{3}$ с добавлением ЦТАБ $\left(8 \cdot 10^{-4} \mathrm{M}\right)$ или пуллулана $(0.065$ мас.\%). Добавка раствора $\mathrm{SnCl}_{4}$ (In:Sn=9:1 по массе) не снижает устойчивости золей.

Определены условия применимости различных методов нанесения золей на подложку в зависимости от их химического состава. Так, метод центрифугирования (10 слоев) в присутствии ЦТАБ не смог обеспечить равномерного распределения и достаточной адгезии частиц золя к поверхности стекла. В то же время добавка пуллулана положительно влияет на распределение частиц прекурсора по подложке при проведении центрифугирования. Прекурсор равномерно распределяется центробежными силами, и, благодаря поленкообразующим свойствам пуллулана образуется сплошное покрытие без видимых разрывов.

Золи, стабилизированные ЦТАБ, формируют равномерные проводящие пленки $\operatorname{In}_{2} \mathrm{O}_{3}$ при использовании спрей-метода. Однако в этом случае необходимо нанесение большого количества слоев (25 слоев) с сушкой каждого из них и, следовательно, требуются большие временные затраты.

Синтезированные с помощью спрей-метода в присутствии ЦТАБ пленки $\operatorname{In}_{2} \mathrm{O}_{3}$ имели удельное сопротивление 9 Ом·см и толщину 400-500 нм, а полученные центрифугированием пленки ITO обладали удельным сопротивлением 0.1 Ом·см и толщиной 200-250 нм. Обе пленки демонстрировали высокую прозрачность в широком интервале длин волн. Полученные в данной работе пленки сопоставимы по свойствам с материалами, формирующимися как в ходе плазменно-термического испарения, так и синтезированными растворными методами.

$$
-55-
$$


Однако предлагаемый метод более прост технологически, не требует сложного оборудования, а также более экологичен, поскольку не предполагает использования органических растворителей и экстрагентов. По данным РФА, в результате отжига пленка ITO представляет собой не просто смесь наночастиц оксида индия и оксида олова, полученных из соответствующих золей, а именно твердый раствор одного оксида в другом, что показывает эффективность применяемой технологии и дает важные перспективы в технологии прозрачных проводящих покрытий.

\section{Благодарности / Acknowledgments}

Работа выполнена при поддержке РФФИ (грант № 18-33-00504) и стипендии Президента Российской Федерации (СП-2235.2019.1). В работе использованы приборы ЦКП СФУ и Красноярского регионального центра коллективного пользования ФИЦ КНЦ СО РАН.

This work was supported by the Russian Foundation for Basic Research (Grant No. 18-33-00504) and a scholarship from the President of the Russian Federation (SP-2235.2019.1). We are grateful to the Centre of collective usage of the Siberian Federal University and Krasnoyarsk Regional Center of Research Equipment of Federal Research Center «Krasnoyarsk Science Center SB RAS».

\section{Список литературы / References}

1. Granqvist C. G. Transparent conductors as solar energy materials: A panoramic review. Solar Energy Materials and Solar Cells. 2007. Vol. 91 (17), P. 1529-1598.

2. Exarhos G.J., Zhou X.D. Discovery-based design of transparent conducting oxide films. Thin Solid Films. 2007. Vol. 515 (18), P. 7025-7052.

3. Lu J.G., Chang P. C., Fan Z. Y. Quasi-one-dimensional metal oxide materials - Synthesis, properties and applications. Materials Science \& Engineering R-Reports. 2006. Vol. 52 (1-3), P. 49-91.

4. Afre R.A., Sharma N., Sharon M., Sharon M. Transparent Conducting Oxide Films for Various Applications: A Review. Reviews on advanced materials science. 2018. Vol. 53(1), P. 79-89.

5. Freeman A.J., Poeppelmeier K. R., Mason T. Q., Chang R.P., Marks T. J. Chemical and thinFilm strategies for new transparent conducting oxides. Journal of Materials Research Society Bullet. 2000. Vol. 25 (8), P. 45-51.

6. Pasquarelli R.M., Ginley D.S., O'Hayre R. Solution processing of transparent conductors: from flask to film. Chem. Soc. Rev. 2011. Vol. 40, P. 5406-5441.

7. Karthikeyan S., Hill A.E., Pilkington R.D. The deposition of low temperature sputtered $\mathrm{In}_{2} \mathrm{O}_{3}$ films using pulsed d. c. magnetron sputtering from a powder target. Thin Solid Films. 2014. Vol. 550, P. 140-144.

8. Ghorannevis Z., Akbarnejad E., Ghoranneviss M. Structural and morphological properties of ITO thin films grown by magnetron sputtering. J. Theor. Appl. Phys. 2015. Vol. 9, P. 285-290.

9. Kim D., Han Y., Cho J.-S., Koh S.-K. Low temperature deposition of ITO thin films by ion beam sputtering. Thin Solid Films. 2000. Vol. 377-378, P. 81-86.

10. Krylov P.N., Zakirova R. M., Fedotova I. V. Optical properties of ITO films obtained by highfrequency magnetron sputtering with accompanying ion treatment. Semiconductors. 2013. Vol. 47(10), P. 1412-1415. 
11. Cho S. Structural, optical, and electrical properties of RF-sputtered indium oxide thin films. Journal of the Korean Physical Society. 2012. Vol. 60(12), P. 2058-2062.

12. Palomares-Sanchez S. A., Watts B.E., Klimm D., Baraldi A., Parisini A., Vantaggio S., Fornari R. Sol-gel growth and characterization of $\mathrm{In}_{2} \mathrm{O}_{3}$ thin films. Thin Solid Films. 2018. Vol. 645, P. 383-390.

13. Sunde T.O.L., Garskaite E., Otter B., Fossheim H.E., Saterli R., Holmestad R., Einarsrud M. A., Grande T. Transparent and conducting ITO thin films by spin coating of an aqueous precursor solution. Journal of Materials Chemistry. 2012. Vol. 22(31), P. 15740-15749.

14. Nishinaka H., Yoshimoto M. Mist Chemical Vapor Deposition of Single-Phase Metastable Rhombohedral Indium Tin Oxide Epitaxial Thin Films with High Electrical Conductivity and Transparency on Various $\alpha-\mathrm{Al}_{2} \mathrm{O}_{3}$ Substrates. Crystal Growth \& Design. 2018. Vol. 18(7), P. 4022-4028.

15. Li Z.L., Zhou J.Y., Wang Z.P., Gu J.H., Zhang Y.W., Wei Y.X. Preparation of Flowerlike Indium Oxide Films by a Simple CVD Method. Advanced Materials Research 2012. Vol. 567, P. 41-44.

16. Патент РФ 2587083. Пашков Г. Л., Сайкова С. В., Пантелеева М. В., Евсевская Н. П. Способ получения высокодисперсных порошков оксида индия. Опубл. 10.06.2016. [Patent 2587083 RU. Pashkov G. L., Saikova S. V., Panteleeva M. V. Evsevskaya N. P. Method of producing fine powders of indium oxide. Publ. Date 10.06.2016 (In Russ.)]

17. Pashkov G.L., Saikova S. V., Panteleeva M. V. Reactive ion exchange processes of nonferrous metal leaching and dispersion material synthesis. Theor. Found. Chem. Eng. 2016. Vol. 50, P. 575-581.

18. Bovina E.A., Tarasova D. V., Soderzhinova M. M., Dulina R. S., Chibirova F. K.. Synthesis of yttrium hydroxide hydrosols. Rus. J. Inorg. Chem. 2011. Vol. 56(1), P. 1-5.

19. Kobayashi Y., Morimoto H., Nakagawa T., Kubota Y., Gonda K., Ohuchi N. Fabrication of gadolinium hydroxide nanoparticles using ion-exchange resin and their MRI property. J. Asian Ceram. Soc. 2016. Vol. 4, P. 138-142.

20. Evsevskaya N., Pikurova E., Saikova S. V., Nemtsev I. V. Effect of the deposition conditions on the anion resin exchange precipitation of indium (III) hydroxide. ACS Omega. 2020. Vol. 5, P. 4542-4547.

21. Saikova, S.V., Kirshneva, E.A., Panteleeva, M.V., Pikurova, E.V., Evsevskaya, N. P. Production of Gadolinium Iron Garnet by Anion Exchange resin Precipitation. Rus. J. Inorg. Chem. 2019. Vol. 64, P. 1191-1198.

22. Park K.S., Choi Y.J., Kang J.G., Sung Y.M., Park, J.G. The effect of the concentration and oxidation state of $\mathrm{Sn}$ on the structural and electrical properties of indium tin oxide nanowires. Nanotechnology. 2011. Vol. 22(28), 285712.

23. Rembeza S., Voronov P., Rembeza E. Synthesis and physical properties of nanocomposites $\left(\mathrm{SnO}_{2}\right)_{\mathrm{x}}\left(\mathrm{In}_{2} \mathrm{O}_{3}\right)_{1-\mathrm{x}}(\mathrm{x}=0-1)$ for gas sensors and optoelectronics. Sensors \& Transducers Journal. 2010. Vol. 122(11), P. 46-54.

24. Воронин А.С., Иванченко Ф.С., Симунин М. М., Лямкин А.И., Фадеев Ю. В., Шиверский А.В., Хартов С.В. Модифицирование spray-метода для получения пленок однослойных углеродных нанотрубок и их свойства. Журнал СФУ. Техника и технологии. 2015. Т. 8 (2), С. 146152. [Voronin A. S. Ivanchenko F. S., Simunin M.M., Lyamkin A.I., Fadeev Y.V. Shiverskiy A.V., Khartov S. V. Modification of spray-method for producing of single-walled carbon nanotubes films and their properties. Journal of Siberian Federal University. Engineering \& Technologies. 2015. Vol. 2(8), P. 146-152. (In Russ.)]. 
25. Патент РФ 2587083. Пашков Г. Л., Сайкова С. В., Пантелеева М. В., Евсевская Н. П. Способ получения высокодисперсных порошков оксида индия. Опубл. 10.06.2016. [Patent 2587083 RU. Pashkov G. L., Saikova S. V., Panteleeva M. V. Evsevskaya N.P. Method of producing fine powders of indium oxide. Publ. Date 10.06.2016 (In Russ.)].

26. Сайкова С.В., Пашков Г.Л., Пантелеева М.В. Реакционно-ионообменные процессы извлечения цветных металлов и синтеза дисперсных материалов: монография. Красноярск: Сиб. федер. ун-т, 2018. 198 с. [Saikova S. V., Pashkov G. L., Panteleeva M. V. Reaction-ion-exchange processes for the extraction of non-ferrous metals and the synthesis of dispersed materials: monograph. Krasnoyarsk: Sib. Feder. un-t, 2018. 198 p. (In Russ.)].

27. Фролов Г. Ю. Курс коллоидной химии. Поверхностные явления и дисперсные системы. М.: Химия, 1989. 464 с. [Frolov G. U. Colloidal chemistry course. Surface phenomena and dispersed systems. M.: Chemistry, 1989. 464 p. (In Russ.)].

28. Kuni F.M., Shchekin A.K., Rusanov A.I., Grinin, A.P. Boltzmann Distributions and Slow Relaxation in Systems with Spherical and Cylindrical Micelles. Langmuir. 2006. Vol. 22(4), P. 15341543 .

29. Sahu N., Parija B., Panigrahi S. Fundamental understanding and modeling of spin coating process: A review. Indian J. Phys. 2009. Vol. 83(4), P. 493-502.

30. Schubert D.W., Dunkel T. Spin coating from a molecular point of view: its concentration regimes, influence of molar mass and distribution. Materials Research Innovations. 2003. Vol. 7(5), P. 314-321.

31. Nadaud N., Lequeux N., Nanot M., Jove J., Roisnel T. J. Structural studies of tin-doped indium oxide (ITO) and $\mathrm{In}_{4} \mathrm{Sn}_{3} \mathrm{O}_{12}$. Solid State Chem. 1998. Vol. 135, P. 140-148.

32. Kim H., Gilmore C.M., Pique A., Horwitz J.S., Mattoussi H., Murata H., Kafafi Z.H., Chrisey D. B. Electrical, optical, and structural properties of indium-tin-oxide thin films for organic light-emitting devices. J. Appl. Phys. 1999. Vol. 86, P. 6451-6461.

33. Naik G.V., Shalaev V.M., Boltasseva A. Alternative Plasmonic Materials: Beyond Gold and Silver. Adv. Mater. 2013. Vol. 25(24), P. 3264-3294.

34. Ilin A.S., Matsukatova A.N., Forsh P. A., Vygranenko Y. Electrical Properties of IndiumOxide Thin Films Produced by Plasma-Enhanced Reactive Thermal Evaporation. Semiconductors. 2018. Vol. 52(12), P. 1638-1641.

35. Патент РФ 2491372. Патрушева Т. Н., Снежко Н. Ю., Патрушев В. В. Способ получения прозрачной проводящей пленки InSnO. Опубл. 27.08.2013. [Patent 2491372 RU. Patrusheva T. N., Snezhko N.J., Patrushev V.V. Method to produce transparent conducting film InSnO. Publ. Date 27.08.2013. (In Russ.)].

36. Патент РФ 2656916. Левашов А.С., Бурый Д.С., Латыпова А.Р. Способ получения тонких пленок оксида олова-индия. Опубл. 07.06.2018. [Patent 2656916 RU. Levashov A.S., Buryj D. S., Latypova A. R. Method of obtaining thin films of tin-indium oxide. Publ. Date 07.06.2018 (In Russ.)].

37. Патрушева Т.Н. Технологии изготовления компонентов оксидных солнечных батарей. Монография. Красноярск: Сиб. Федер. ун-т. 2015. 328 с. [Patrusheva T. N. Manufacturing technologies for oxide solar cell components. Monograph. Krasnoyarsk: Sib. Feder. un-t. 2015. 328 p. (In Russ.)]. 